\title{
Pharmacokinetic and pharmacodynamic characterization of a mediummolecularweight heparin in comparison with UFH and LMWH.
}

Citation for published version (APA):

Alban, S., Welzel, D., \& Hemker, H. C. (2002). Pharmacokinetic and pharmacodynamic characterization of a mediummolecularweight heparin in comparison with UFH and LMWH. Seminars in Thrombosis and Hemostasis, 28, 369-378. https://doi.org/10.1055/s-2002-34306

Document status and date:

Published: 01/01/2002

DOI:

10.1055/s-2002-34306

Document Version:

Publisher's PDF, also known as Version of record

Please check the document version of this publication:

- A submitted manuscript is the version of the article upon submission and before peer-review. There can be important differences between the submitted version and the official published version of record.

People interested in the research are advised to contact the author for the final version of the publication, or visit the DOI to the publisher's website.

- The final author version and the galley proof are versions of the publication after peer review.

- The final published version features the final layout of the paper including the volume, issue and page numbers.

Link to publication

\footnotetext{
General rights rights.

- You may freely distribute the URL identifying the publication in the public portal. please follow below link for the End User Agreement:

www.umlib.nl/taverne-license

Take down policy

If you believe that this document breaches copyright please contact us at:

repository@maastrichtuniversity.nl

providing details and we will investigate your claim.
}

Copyright and moral rights for the publications made accessible in the public portal are retained by the authors and/or other copyright owners and it is a condition of accessing publications that users recognise and abide by the legal requirements associated with these

- Users may download and print one copy of any publication from the public portal for the purpose of private study or research.

- You may not further distribute the material or use it for any profit-making activity or commercial gain

If the publication is distributed under the terms of Article 25fa of the Dutch Copyright Act, indicated by the "Taverne" license above, 


\title{
Pharmacokinetic and Pharmacodynamic Characterization of a Medium-Molecular- Weight Heparin in Comparison with UFH and LMWH
}

\author{
Susanne Alban, Ph.D., 1 Dieter Welzel, M.D., 1 and H. Coenraad Hemker, Ph.D.2
}

Despite the well-established medical use of heparins, the question arises whether the efficacy-safety ratio of the available heparins can still be improved. Therefore, a medium-molecular-weight heparin (MMWH), a new heparin with an average molecular weight of $10.5 \mathrm{kDa}$ and a narrow molecular weight range $(9.5$ to $11.5 \mathrm{kDa})$ was developed. Its in vitro activities amount to 174.9 anti-factor $\mathrm{Xa}(\mathrm{aXa}) \mathrm{U} / \mathrm{mg}$ and 170.0 antithrombin (aIIa) $\mathrm{U} / \mathrm{mg}$. In the presented randomized, double-blind, cross-over study in healthy volunteers, the pharmacokinetics and pharmacodynamics of MMWH are compared with those of an unfractionated heparin (UFH) and a low-molecular-weight heparin (LWMH; enoxaparin). After subcutaneous administration of $9000 \mathrm{aXa}-\mathrm{U}$ of either heparin in 16 volunteers, the prolongation of the activated partial thromboplastin time (aPTT), the aXa activity, and the alla activities were determined at 11 time points spread over 24 hours after injection. The ex vivo analysis revealed striking pharmacodynamic and pharmacokinetic differences between the three heparins. UFH had the lowest bioavailability regarding the aPTT, aXa, and aIIa activities. Enoxaparin exhibited only low alla activity but the highest aXa activity. Unlike UFH and enoxaparin, MMWH showed a high recovery of aIIa activity, which suggests that it combines the high potency to inhibit thrombin that characterizes UFH with the high bioavailability of the LMWHs. Consequently, substantially lower doses are needed to bring about effects comparable to those of UFH and LMWH.

KEYWORDS: Unfractionated heparin, medium-molecular-weight heparin, lowmolecular-weight heparin, pharmacokinetics, pharmacodynamics

Objectives: Upon completion of this article, the reader should be able to (1) list some of the properties of a newly developed medium-molecular-weight heparin as compared with unfractionated and low-molecular-weight heparins and (2) describe some of the findings related to the pharmacokinetics and pharmacodynamics of the new compound.

Glycosaminoglycans: Anticoagulant and Nonanticoagulant Actions; Editor in Chief, Eberhard F. Mammen, M.D.; Guest Editors, Job Harenberg, M.D. and Benito Casu, Ph.D. Seminars in Thrombosis and Hemostasis, volume 28, number 4, 2002. Address for correspondence and reprint requests: Susanne Alban, Ph.D., Institute of Pharmacy, University of Regensburg, Universitätsstr. 31, 93040 Regensburg, Germany. Email: Susanne.Alban@chemie.uni-regensburg.de. 1'Institute of Pharmacy, University of Regensburg, Regensburg, Germany and 2Department of Biochemistry and Synapse BV, Cardiovascular Research Institute (CARIM), Maastricht, The Netherlands. Copyright (C) 2002 by Thieme Medical Publishers, Inc., 333 Seventh Avenue, New York, NY 10001, USA. Tel: +1(212) 584-4662. 0094-6176,p;2002,28,04,369,378, ftx,en;sth00813x. 
Accreditation: Tufts University School of Medicine is accredited by the Accreditation Council for Continuing Medical Education to provide continuing medical education for physicians. TUSM takes full responsibility for the content, quality, and scientific integrity of this continuing education activity.

Credit: Tufts University School of Medicine designates this education activity for a maximum of 1.0 hours credit toward the AMA Physicians Recognition Award in category one. Each physician should claim only those hours that he/she actually spent in the educational activity.

For more than 60 years, unfractionated heparin (UFH) has been the drug of choice in the prophylaxis and treatment of thromboembolic disorders. ${ }^{1}$ After two decades of intensive research, low-molecular-weight heparins (LMWHs) became more and more important and tend to replace UFH. ${ }^{1}$ They turned out to be at least as safe and effective as UFH for the prevention and treatment of venous thromboembolism and have been used successfully in patients with unstable angina. ${ }^{2}$ Because of their decreased propensity to bind to plasma proteins, ${ }^{3}$ endothelial cells, ${ }^{4}$ and macrophages, ${ }^{1,3}$ LMWHs show some pharmacokinetic advantages over UFH so that for prophylaxis, once-daily subcutaneous (s.c.) application is sufficient.

In view of the outcome of clinical studies, ${ }^{1,5}$ the benefit of heparins in general has been doubtless proved. Nevertheless, there is still need for further improvement of antithrombotic strategies. Especially in high-risk patients, such as elderly or tumor patients, a high residual incidence of thromboembolic complications is observed despite prophylactic measures. However, the established prophylactic regimens with the available heparins can hardly be improved. An increase in the dose is generally associated with a higher bleeding risk. ${ }^{4}$

Because of this unsatisfactory situation, an important focus of research is the development of new antithrombotics, different from heparin., 6 But the ideal drug has not yet been discovered. All of them have the imminent risk of inducing bleeding. Due to the key functions of thrombin in thrombogenesis, the control of thrombin generation and thrombin action represents an important target. ${ }^{6}$ One strategy is the design of specific factor $\mathrm{Xa}(\mathrm{FXa})$ and irreversible or reversible thrombin inhibitors such as fondaparinux, hirudin, and melagatran. ${ }^{8-10}$ Irreversible inhibition of thrombin primarily acts as an inhibitor of the thrombin-mediated positive feedback activation and thus retards thrombin generation, but it is ultimately unable to prevent the explosive appearance of thrombin. ${ }^{11,12}$ At concentrations that approach those of (pro-)thrombin potentially available, the danger of too much inhibition and hence of bleeding is imminent. Reversible inhibitors theoretically can never inhibit thrombin completely and therefore may offer a broader therapeutic window than irreversible inhibitors do. In contrast to the direct thrombin inhibitors, FXa inhibitors do not delay but efficiently decrease thrombin generation as shown in whole blood. ${ }^{11}$ However, on the basis of antiFXa (aXa) activity, about 20 -fold higher concentrations are required for an effect similar to that of heparin. This is suggested to be due to the six times higher plasma concentrations of FX compared with FV, so that $90 \%$ inhibition of $\mathrm{FXa}$ is required to obtain just $50 \%$ inhibition of the thrombin-generating prothrombinase. ${ }^{13}$

In contrast to this, heparin delays as well as decreases thrombin generation in whole blood. ${ }^{11}$ Heparin inhibits both thrombin and FXa by catalyzing their inactivation by antithrombin (AT). For the antithrombotic activity, the inhibition of $\mathrm{FXa}$, however, has proved to be of minor importance, as can be expected for the reasons mentioned earlier. ${ }^{14}$ In addition to its AT-dependent anticoagulant actions, heparin releases tissue factor pathway inhibitor (TFPI) from endothelium into circulating blood. ${ }^{15}$ This endogenous coagulation inhibitor acts synergistically with heparin ${ }^{16}$ and is supposed to contribute to the overall antithrombotic activity of heparin. ${ }^{17,18}$ A further advantage of heparin is its manifold additional biological activities. ${ }^{19}$ At present, these actions are discussed as possibly supporting the therapeutic benefit of heparin (e.g., as found in tumor patients). ${ }^{20}$

For these reasons, it is worth asking whether there is any option for improving the benefit-risk ratio of heparin.

Heparin is a polydisperse mixture of glycosaminoglycans with molecular weight (MW) ranging from 5 to $40 \mathrm{kDa}$ and an average $\mathrm{MW}$ of $13 \mathrm{kDa}$ showing great structural complexity. ${ }^{19,21}$ To exhibit AT-mediated anticoagulant activity, the heparin molecules must contain a specific AT-binding pentasaccharide sequence. ${ }^{22}$ The percentage of this so-called high-affinity material varies and is in general related to the average MW. It ranges from about $50 \%$ in UFH to $10 \%$ in some types of LMWH. ${ }^{12}$ Only molecules consisting of more than 17 monosaccharides $(>5.4 \mathrm{kDa})$ are able to inactivate both FXa and thrombin. Accordingly, the high-affinity material is subdivided into below the critical chain length material (BCLM) showing only aXa activity and above the critical chain length material (ACLM) with aXa as well as aII a activity. A special class of heparin molecules is those with high MW (about $>13 \mathrm{kDa}$ ), which are absent in LMWH and are postulated to be responsible for the low bioavailability of UFH administered s.c. and the induction of bleeding. For the mobilization of TFPI, heparin does not require the AT-binding site, ${ }^{23}$ but this action of heparin is strongly dependent on its MW. ${ }^{24}$

Based on these facts and on the knowledge that the aXa activity of heparin does not contribute significantly to its antithrombotic efficacy, ${ }^{14}$ the available LMWHs may not represent the optimal heparin. Al- 
though their bioavailability after s.c. administration is high compared with UFH, their specific anticoagulant activities, especially their alla activity, are lower. A heparin with a relatively high MW but lacking the extra long heparin chains might combine the potent anticoagulant action of UFH with the high bioavailability of the LMWHs and maintain a pronounced TFPI-releasing effect. We therefore developed a heparin with a narrow MW distribution around $10.5 \mathrm{kDa}(\mathrm{MMWH})$. In animal experiments, it proved to be more efficient and safer than UFH and LMWH (J. Fareed et al, unpublished data, 1999). In the present study we compared the pharmacokinetics and pharmacodynamics of MMWH with those of an UFH and a LWMH after s.c. administration in healthy volunteers.

\section{MATERIALS AND METHODS}

\section{Heparins}

Three different heparins were investigated: UFH (Liquemin ${ }^{\circledR}$ N, Hoffmann-LaRoche AG, Basel, Switzerland), MMWH (provided by Biochemie $\mathrm{GmbH}$, Schaftenau, Austria), and enoxaparin $\left(\right.$ Clexane $^{\circledR}$, Aventis Pharma, Frankfurt, Germany). The three heparins are isolated from porcine intestinal mucosa and are used as sodium salts. The production methods, the MW distributions, and the specific aXa and aIIa activities are shown in Table 1. Prefilled glass syringes containing $9000 \mathrm{aXa}-\mathrm{U}$ of either heparin were used for s.c. injection.

\section{Subjects}

Sixteen healthy normolipemic male students at the University of Regensburg of mean age $25.9 \pm 3.3$ years (mean $\pm \mathrm{SD}$, range 18-30 years), mean body weight $79.8 \pm 12.1 \mathrm{~kg}$ (range 60.0-95.0 kg), mean height $181.6 \pm 9.0 \mathrm{~cm}$ (range 167-198 cm), and mean BMI
$24.1 \pm 2.7 \mathrm{~kg} / \mathrm{m}^{2}$ (range $20.9-29.3 \mathrm{~kg} / \mathrm{m}^{2}$ ) were recruited. All subjects provided written informed consent.

Volunteers were healthy as determined by medical history, physical examination, blood pressure measurements, hepatitis and human immunodeficiency virus serologies, and routine biochemical, hematologi$\mathrm{cal}$, and hemostatic tests including platelet counts, activated partial thromboplastin time (aPTT), and prothrombin time. They neither suffered from any local or general hemorrhagic diathesis nor had any previous thrombotic disease. There was no contraindication for the application of heparin. No other medications were taken for 4 weeks before study entry and during the trial. On the days of pharmacokinetic profiling, subjects were given a scheduled standardized diet. They were not allowed to consume alcohol or caffeine-containing products within 48 hours of drug administration and were asked to avoid strenuous physical exercise. One week after the last treatment period, all routine biochemical tests were redone, resulting in no significant changes compared with the prestudy examinations.

\section{Study Design}

The study protocol was approved by the local Ethics Committee (Ethikkommission der Bayerischen Ärztekammer) and was performed in accordance with the Declaration of Helsinki and with European Community Guidelines for good clinical practices.

The study was designed as a monocentric, randomized, double-blind, three-period cross-over trial. According to the randomization scheme, each volunteer was given a single s.c. injection of $9000 \mathrm{aXa}-\mathrm{U}$ of either heparin. A 1-week washout period followed each heparin administration.

Venous blood for the determination of pharmacokinetic profiles was collected by clean venipuncture (discarding the first $2 \mathrm{~mL}$ of blood) through an 18 -

Table 1 Characterization of the Three Heparins Compared in This Study

\begin{tabular}{|c|c|c|c|}
\hline Characteristics & $\begin{array}{l}\text { UFH } \\
\text { (Liquemin }^{\Phi} \text { ) }\end{array}$ & MMWH & $\begin{array}{l}\text { Enoxaparin } \\
\left.\text { (Clexane }{ }^{\oplus}\right)\end{array}$ \\
\hline Production method* & & $\begin{array}{l}\text { Mild isoamylnitrite } \\
\text { degradation/ } \\
\text { GPC-fractionation }\end{array}$ & $\begin{array}{l}\text { Benzylation/ } \\
\beta \text {-elimination }\end{array}$ \\
\hline Average $\mathrm{MW}(\mathrm{kDa})^{*}$ & $\begin{array}{l}13.0 \\
(3.0-30.0)\end{array}$ & $\begin{array}{l}10.5 \\
(9.5-11.5)^{\dagger}\end{array}$ & $\begin{array}{l}4.5 \\
(3.5-5.5)^{\ddagger}\end{array}$ \\
\hline $\mathrm{aXa}-\mathrm{U} / \mathrm{mg}^{\mathrm{s}}$ & 15.90 & 174.9 & 100.0 \\
\hline alla-U/mg $g^{\xi}$ & 159.0 & 170.0 & 26.3 \\
\hline aXa-/alla activity ratio & 1.00 & 1.03 & 3.80 \\
\hline
\end{tabular}


gauge indwelling cannula (Vasofix ${ }^{\circledR}$ Braunüle $^{\circledR}$ and Mandrin ${ }^{\circledR}$, B. Braun Melsungen, Melsungen, Germany) into S-Monovettes ${ }^{\circledR}$ (Sarstedt, Nümbrecht, Germany) containing $0.106 \mathrm{M}$ sodium citrate $(9: 1 \mathrm{v} / \mathrm{v})$. Blood samples were drawn before and $0.5,1,1.5,2,3,4$, $5,8,10$, and 24 hours after heparin administration. According to the guidelines for preparing citrated plasma for hemostaseological analyses, ${ }^{25}$ platelet-poor plasma was prepared by centrifugation at $3000 \mathrm{~g}$ for 20 minutes at $15^{\circ} \mathrm{C}$, transferred into cryovials in aliquots of $0.5 \mathrm{~mL}$, frozen in liquid nitrogen, and stored at $-70^{\circ} \mathrm{C}$ until further analysis.

\section{APTT, aXa, and alla Activity}

The biological markers used to define the pharmacokinetic profile of the three heparins were the anticoagulant activity in the aPTT and the inhibition of FXa and thrombin. All analyses were performed on an ACL 3000 (Instrumentation Laboratory, Kirchheim, Germany). Duplicate values were generally determined. If the deviation was more than $3 \%$, the measurement was repeated. The validity of each determination was checked by parallel controls with control plasma, the Fourth International Standard for heparin (1983), or the First International Standard for LMWH (National Institute for Biological Standards and Control, London, UK).

The aPTT activity was determined as prolongation of the baseline clotting time using a commercial kit according to the instructions of the manufacturer (APTT Micro Kieselgur, Instrumentation Laboratory).

Plasma aXa and alla activities were measured by amidolytic assays using reagents from Chromogenix $\mathrm{AB}$ (Mölndal, Sweden). Plasma samples diluted with AT containing TRIS buffer were incubated with bovine FXa and bovine thrombin, respectively. After mixing with the chromogenic substrates S2222 and S2238, respectively, the amidolysis was recorded at $405 \mathrm{~nm}$ for 120 seconds. The resulting absorbance was calculated as percent inhibition of FXa and thrombin, respectively, by means of the baseline absorbance. The lowest sensitivity was $0.02 \mathrm{U} / \mathrm{mL}$ for both assays. The intra- and interday relative standard deviations were less than $5 \%$.

\section{Pharmacokinetic Analysis}

The noncompartmental pharmacokinetic parameters were evaluated by standard methods. ${ }^{26}$ The maximum effects in the plasma samples expressed as prolongation of the aPTT, percent inhibition of FXa and thrombin $\left(c_{\max }\right)$, their time of appearance $\left(t_{\max }\right)$, and the areas under plasma curves (AUCs) were determined for each subject from the observed data without curve fitting. The $\mathrm{AUC}_{0-24 \mathrm{~h}}$ was calculated using the trapezoidal rule. ${ }^{27}$ For the calculation of the $\mathrm{AUC}_{0-24 \mathrm{~h}}$ adjusted to the same gravimetric dose $(1 \mathrm{mg})$, the $\mathrm{AUC}_{0-24 \mathrm{~h}}$ values were divided by the given gravimetric heparin dose, that is, $56.6 \mathrm{mg} \mathrm{MMWH}, 51.5 \mathrm{mg} \mathrm{UFH}$, and $90.0 \mathrm{mg}$ enoxaparin.

The time courses of activities after s.c. administration of the three different heparins were best described by a biexponential curve (Bateman function) fitting. The apparent invasion half-life $\mathrm{t} 1 / 2_{\mathrm{inv}}$ was calculated from the ascending part of the plasma concentration-activity time curves $\left(\mathrm{t} 1 / 2_{\text {inv }}=\ln 2 / \mathrm{k}_{\text {inv }}\right)$. The elimination rate constant $\left(\mathrm{k}_{\mathrm{el}}\right)$ and the terminal half-live $t 1 / 2_{c l}$ were obtained from the descending phase of the semilogarithmic plasma concentration-activity time curves using linear regression analysis $\left(\mathrm{t} 1 / 2_{\mathrm{el}}=\ln 2 / \mathrm{k}_{\mathrm{cl}}\right)$. Furthermore, the mean residence time (MRT) was determined using the fitted plasma concentration-activity curves. MRT corresponds to the time at which $63.2 \%$ of the total AUC is achieved and is calculated as MRT = AUMC/AUC, where AUMC is the area under the first moment curve. ${ }^{28}$

\section{Statistical Analysis}

All results were determined as mean \pm SD (standard deviation). All parameters were subsequently subjected to general linear model (GLM) of analysis of variance (three-way Latin square ANOVA) by randomized block design. Pairwise comparisons between the three heparins were made by contrast using a significance level $(\alpha)$ of 0.05 . Differences were regarded as statistically significant when $p<.05$. All statistical calculations were performed using a Generica Software package. ${ }^{29}$

\section{RESULTS}

\section{Clinical Observations and Safety profile}

All volunteers completed the study. The s.c. administration of $9000 \mathrm{aXa}-\mathrm{U}$ of MMWH, UFH, and enoxaparin was well tolerated. No adverse events or bleeding complications were observed during the experiments and at the poststudy examination.

\section{APTT, aXa, and alla Activity}

Mean plasma activities in the aPTT, aXa, and alla assays as a function of time after s.c. administration of the three heparins are illustrated in Figure 1. MMWH was more efficacious than enoxaparin and UFH in the aPTT and especially in the aIla assay. In the aXa assay, enoxaparin proved to be the most active, followed by MMWH and finally UFH with the weakest effect.

The different anticoagulant potencies of the three heparins become obvious from the $\mathrm{AUC}_{0-24 \mathrm{~h}}$ of the activities in the three assays. They were calculated on the basis of the respective effects, that is, the prolongation 
of clotting time and inhibition of $\mathrm{FXa}$ and thrombin (Fig. 2). According to the varying order of the $\mathrm{AUC}_{0-24 \mathrm{~h}}$ values in the three assays, the three heparins differed significantly not only in their pharmacokinetic but also in their pharmacodynamic profiles. The mean $\mathrm{AUC}_{0-24 \mathrm{~h}}$ values of $\mathrm{MMWH}$ were generally higher than those of UFH: 1.48 times in the aPTT, 2.00 times in the aXa, and 1.77 times in the alla assay. In the aPTT and the aIla assay, it was also more active than enoxaparin (1.23 times and 1.52 times, respectively); in the aXa assay, its activity was 2.34 times lower than that of enoxaparin. Compared with UFH, enoxaparin showed 4.69 times higher aXa activity, but its effects in the aPTT and aIIa assay were only moderately better.
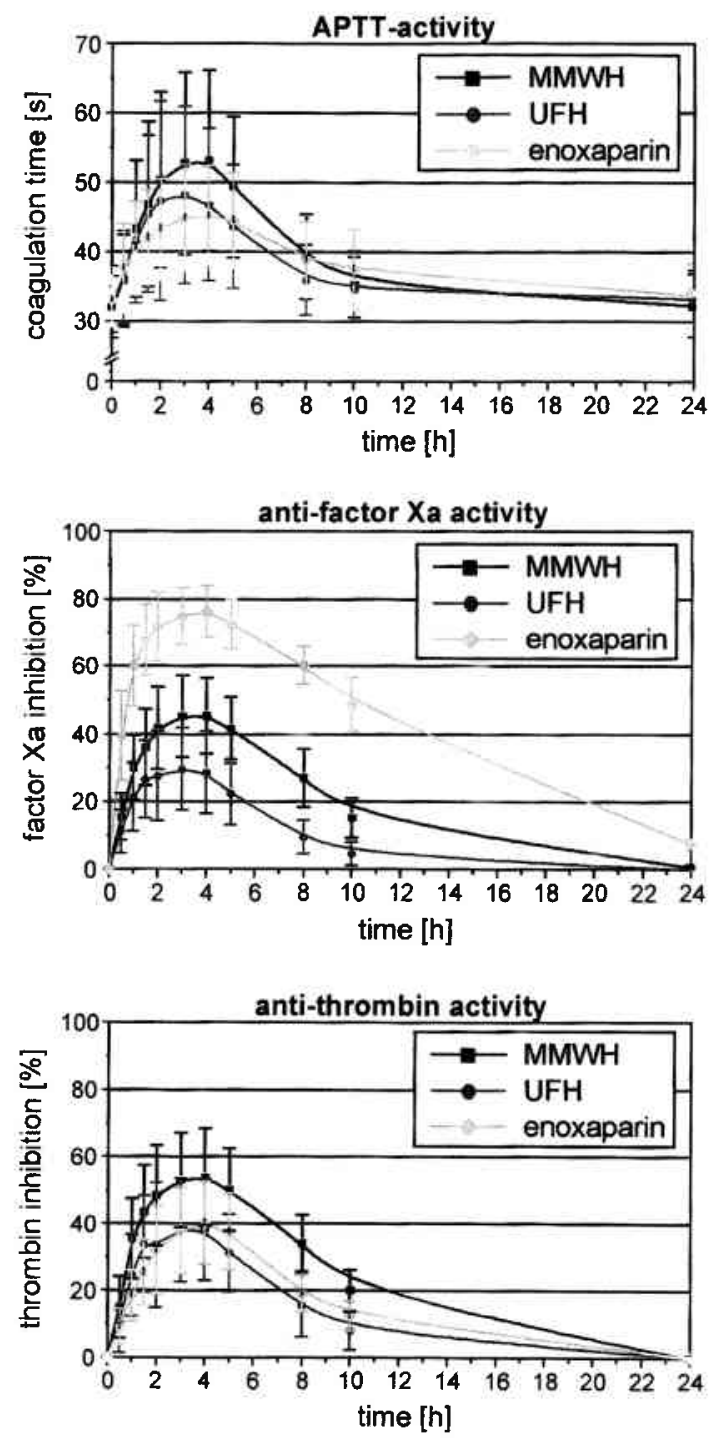

Figure 1 Time-dependent mean ( $n=16, \pm S D$ ) coagulation times (seconds) in aPTT (aPTT activity) and inhibition (\%) of FXa (aXa activity) and thrombin (alla activity) measured in the plasma samples obtained after single s.c. administration of $9000 \mathrm{aXa}-\mathrm{U}$ of MMWH, UFH, and enoxaparin.
Similar tendencies as for the $\mathrm{AUC}_{0-24 \mathrm{~h}}$ were found for the effect-based $c_{\max }$, but the differences between the three heparins were smaller (Table 2). An exception was the $c_{\max }$ of enoxaparin in the aPTT. In contrast to its $\mathrm{AUC}_{0-24 \mathrm{~h}}$, it was not only lower (43\%) than that of MMWH but also lower than that of UFH (25\%).

\section{Comparison on a Weight Basis}

According to the usual practice, equal doses of aXa activity of each heparin were administered. However, based on the specific activities (aXa-U/mg) of the three heparins, these correspond to $51.5 \mathrm{mg} \mathrm{MMWH}, 56.5$ $\mathrm{mg} U \mathrm{UH}$, and $90 \mathrm{mg}$ enoxaparin. When compared on a weight basis, the $\mathrm{AUC}_{0-24 \mathrm{~h}}$ and $\mathrm{c}_{\max }$ differences between MMWH and UFH increased by about $10 \%$ in favor of MMWH and those with enoxaparin by as much as $75 \%$ (Fig. 3).

\section{Pharmacokinetic Parameters}

We determined the pharmacokinetic parameters $t_{\text {max }}$, $\mathrm{t} 1 / 2_{\text {inv }}, \mathrm{t} 1 / 2_{\text {el }}$ (minutes), and MRT (hours) (Table 2). The differences in these parameters are less obvious than those in $\mathrm{c}_{\max }$; nevertheless, MMWH differed significantly from either or both UFH and enoxaparin in $\mathrm{aX} \mathrm{a}, \mathrm{aII}$, and aPTT activities.

Its $t_{\max }$ values of about 4 hours approximately corresponded to those of LWMH and were on average $30 \%$ longer than those of UFH.

The $t 1 / 2_{\text {inv }}$ varied between about 1 and 2 hours. Due to its high $\mathrm{c}_{\max }$, the $t 1 / 2_{\text {inv }}$ values of $M M W H$ were longer than those of UFH, but the appearance of its activities was faster (Fig. 1). The aPTT and aIla activity of MMWH also appeared faster than those of enoxaparin. However, in the $\mathrm{aXa}$ assay MMWH showed the fastest appearance as well as the shortest $t_{\text {inv }}$. Whereas the $t 1 / 2_{\text {inv }}$ of MMWH did not differ significantly between the three assays, the $t 1 / 2_{\text {inv }}$ of UFH in the aPTT was significantly shorter than those in the aXa and alla assays and the $t 1 / 2_{\text {inv }}$ of enoxaparin in the alla assay was significantly longer that those in the $\mathrm{aPTT}$ and the $\mathrm{aXa}$ assay.

The $t 1 / 2_{\text {el }}$ values were generally longer than the $\mathrm{t} 1 / 2_{\text {inv }}$ ones, ranging between about 2 and 4 hours. Those of MMWH and UFH did not differ significantly. But compared with enoxaparin, the $t 1 / 2$ el values of MMWH in the aPTT and the aXa were significantly shorter, whereas that in the aIIa assay was significantly longer. Comparing the different activities, the aIIa activity of MMWH was eliminated significantly more slowly than its aPTT and aXa activity, whereas inversely the aIla activity of enoxaparin disappeared significantly faster than both its aPTT and aXa activity.

In all three assays, the MRTs were shortest for UFH and longest for enoxaparin. One exception was 
APTT activity

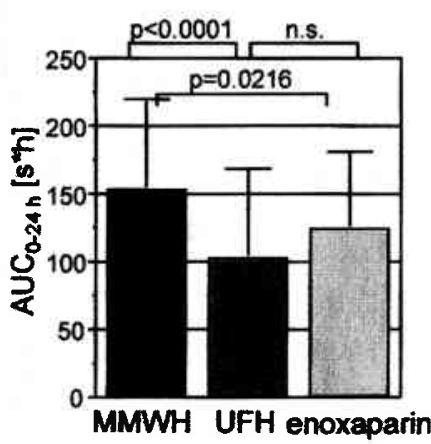

aXa actlvity

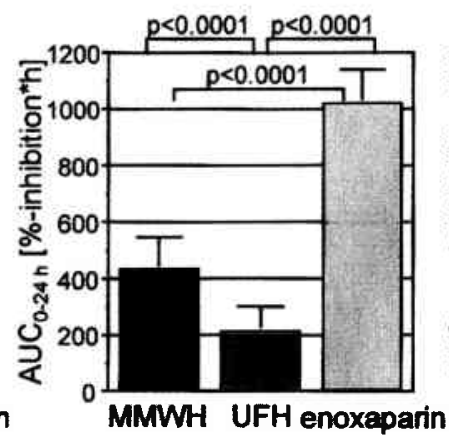

alla activity

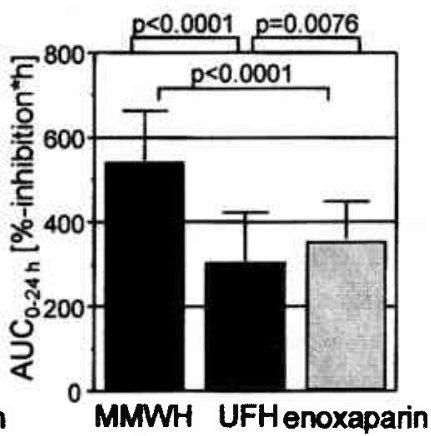

Figure 2 Mean ( $n=16, \pm S D$ ) AUC ${ }_{0-24 h}$ for the aPTT, aXa, and alla activities after single S.c. administration of 9000 aXa-U $M M W H, U F H$, and enoxaparin. The $A \cup C_{0-24 h}$ values are based on the respective effects, that is, the prolongation of the aPT and th percent inhibition of FXa and thrombin. The $p$ values represent the significance level obtained by pairwise comparisons between th three heparins (significant differences: $p<.05$ ) in each case.

the MRT of MMWH in the aIIa assay, which was not only longer than that of UFH but also somewhat longer than that of enoxaparin.

\section{DISCUSSION}

Hemker and colleagues ${ }^{13,14}$ surmised that the main antithrombotic activity of a heparin would be localized in molecules with a definite alla activity and yet small enough to have high bioavailability. Moreover, experiments demonstrated that the aXa activity of heparin is only a partial expression of the therapeutic potential an that the antithrombotic effect improves with increasin chain length of heparin fragments. ${ }^{30-34}$

The new heparin that we tested, MMWH, ha an average MW of $10.5 \mathrm{kDa}$ and a narrow MW rang In contrast to UFH, it does not contain molecules wit MW $>15 \mathrm{kDa}$, which on good grounds can be though to be responsible for hemorrhagic complications. ${ }^{13} \mathrm{I}$ specific aXa and alla activities are $10 \%$ higher tha those of UFH. This indicates that during the produc tion of MMWH the content of high-affinity materi

Table 2 Pharmacokinetic Parameters* for Plasma aPTT, aXa, and alla Activity after Single Subcutaneous Administration of 9000 aXa of MMWH, UFH, and Enoxaparin*

\begin{tabular}{|c|c|c|c|}
\hline & aPTT Activity & aXa Activity & alla Activity \\
\hline \multicolumn{4}{|c|}{$\mathrm{c}_{\max }(\mathrm{s})^{+}$and (\% inhibition) } \\
\hline MMWH & $22.5 \pm 10.7$ & $46.7 \pm 11.5$ & $55.5 \pm 14.3$ \\
\hline UFH & $17.4 \pm 12.7 p .0127$ & $31.4 \pm 12.2 p .0001$ & $41.0 \pm 14.8 p .0001$ \\
\hline Enoxaparin & $13.0 \pm 4.5 p .0001$ & $77.2 \pm 7.9 p .0001$ & $41.3 \pm 12.5 p .0001$ \\
\hline \multicolumn{4}{|l|}{$t_{\max }(\min )$} \\
\hline MMWH & $233 \pm 82$ & $218 \pm 43$ & $221 \pm 46$ \\
\hline UFH & $178 \pm 73 p .0175$ & $171 \pm 46 p .0036$ & $184 \pm 46 p .0081$ \\
\hline Enoxaparin & $240 \pm 49 p .7353$ & $221 \pm 36 \rho .8070$ & $248 \pm 37 p .0588$ \\
\hline \multicolumn{4}{|l|}{$\mathrm{t} 1 / 2_{\text {inv }}(\min )$} \\
\hline MMWH & $105 \pm 17$ & $116 \pm 24$ & $99 \pm 36$ \\
\hline UFH & $67 \pm 37 p .0003$ & $91 \pm 26 p .0057$ & $84 \pm 34 p .0637$ \\
\hline Enoxaparin & $82 \pm 28 p .0224$ & $89 \pm 24 p .0037$ & $122 \pm 22 p .0082$ \\
\hline \multicolumn{4}{|l|}{$\mathrm{t} 1 / 2_{\mathrm{el}}(\mathrm{min})$} \\
\hline MMWH & $129 \pm 68$ & $137 \pm 28$ & $171 \pm 59$ \\
\hline UFH & $153 \pm 107 \rho .7753$ & $115 \pm 40 p .2378$ & $140 \pm 64 p .0572$ \\
\hline Enoxaparin & $225 \pm 126 p .0187$ & $252 \pm 83 p .0001$ & $134 \pm 29 p .0239$ \\
\hline \multicolumn{4}{|l|}{ MRT (h) } \\
\hline MMWH & $8.68 \pm 1.82$ & $9.48 \pm 1.68$ & $9.95 \pm 1.61$ \\
\hline UFH & $7.95 \pm 2.12 p .1656$ & $8.00 \pm 2.14 p .0013$ & $8.53 \pm 2.07 \rho .0094$ \\
\hline Enoxaparin & $9.74 \pm 2.11 p .0461$ & $11.27 \pm 0.96 p .0002$ & $9.50 \pm 2.88 p .4010$ \\
\hline
\end{tabular}

* Data are presented as mean $(n=16) \pm S D$; $P$ values for the comparison between MMWH and UFH and MMWH and enoxaparin, respectively, are shown, $P<0.05$ is significant.

tBasis of the calculation: prolongation of coagulation time.

fDoses administered: $51.5 \mathrm{mg}$ MMWH, $56.5 \mathrm{mg}$ UFH, $90.0 \mathrm{mg}$ enoxaparin. 
APTT activity

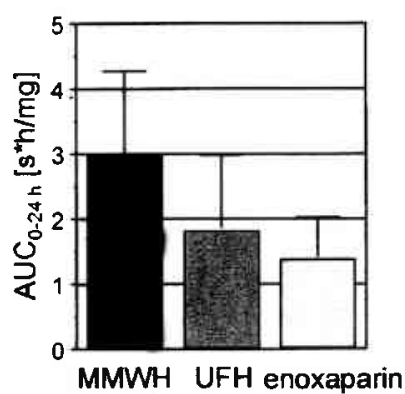

aXa activity

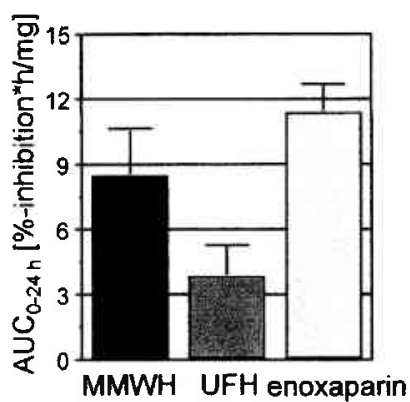

alla activity

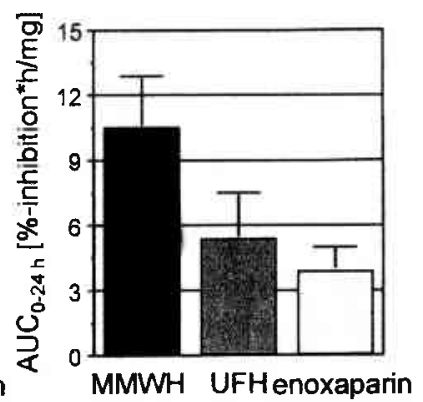

Figure 3 Mean ( $n=16, \pm S D$ ) $A U C_{0-24 h}$ adjusted to the same gravimetric dose $(1 \mathrm{mg})$ of each administered heparin $(51.5 \mathrm{mg}$ MMWH, $56.5 \mathrm{mg} \mathrm{UFH}, 90.0 \mathrm{mg} \mathrm{LMWH}$ ) for the aPTT, aXa, and alla activities after single s.c. administration of $9000 \mathrm{aXa} U$ of MMWH, UFH, and enoxaparin. The AUC $_{0-24 h}$ values are based on the respective effects, that is, the prolongation of the aPTT and the percent inhibition of FXa and thrombin.

remains constant. Hence there is no destruction of the AT binding pentasaccharide sequence, that is, loss of high-affinity binding sites. On a weight basis, the specific aXa activity of MMWH is 1.75 that of enoxaparin; on a molar basis, it is 4 times higher, which is a natural consequence of the fact that upon breakdown of heparin molecules to half their MW the total number of molecules doubles but the number of high-affinity molecules does not increase. Whereas only a small part of the high-affinity material of LWMH exceeds the critical chain length of 17 monosaccharides that makes aIla activity possible, MMWH exclusively consists of such ACLM. Consequently, its specific alla activity is as high as its specific aXa activity.

A heparin fraction with an average MW of about 7.5. $\mathrm{kDa}$ would also have an $\mathrm{aXa} / \mathrm{alla}$ activity ratio of 1.0. But as a result of the stronger degradation its specific activities would be lower than those of MMWH. Also, at lower MW less of the TFPI-releasing effect of heparins is retained. ${ }^{24}$ There are several pharmacological reasons why a MW in the range 9 to $12 \mathrm{kDa}$ must be considered optimal. The bioavailability after s.c. administration of heparin decreases with increasing MW. ${ }^{35}$ High-MW molecules are more readily neutralized by platelet factor $4(\mathrm{PF} 4)^{36}$ and increase the tendency of heparin to induce heparin-induced thrombocytopenia (HIT). ${ }^{37,38}$ Finally, the risk of bleeding should be reduced. $^{30}$ In particular, high-MW molecules with low AT affinity interfere with platelet function and were shown to contribute significantly to hemorrhage but less to the in vivo antithrombotic activity. ${ }^{39,40}$ The absence of molecules larger than $15 \mathrm{kDa}$ in $\mathrm{MMWH}$ and a high content of high-affinity material are two conditions that may contribute to improved safety.

In the present study, the pharmacokinetics and pharmacodynamics of MMWH were compared with those of an UFH and enoxaparin. Both the aPTT and the aXa and alla assays demonstrated that MMWH shows more favorable characteristics than either UFH or enoxaparin. After s.c. administration the bioavailability of $\mathrm{MMWH}$, as judged from the $\mathrm{AUC}_{0-24 \mathrm{~h}}$, is much better. This is more evident in the pharmacokinetic parameters, that is, in the aXa and aIIa activities, than in the pharmacodynamic effect on the aPTT. Comparison of the aPTT data with the inhibition of thrombin generation shows that this must be largely attributed to the aPTT being only a poor indicator of the pharmacodynamic effect of heparin (manuscript in preparation).

Based on the results of this study, half the dose of MMWH is sufficient to obtain aXa and alla activities similar to those after s.c. administration of UFH. Thus, nonspecific anticoagulant effects can be reduced while the specific effects are maintained, which according to Holmer et a $\mathrm{l}^{30}$ and Ockelford et al ${ }^{39}$ would imply an improved benefit-risk ratio.

With the exception of $c_{\max }$ of enoxaparin in the aXa assay, the $c_{\max }$ also followed the trend of $\mathrm{AUC}_{0-24}$, but the differences were smaller. This means that the high AUC is not obtained by dangerously high peak concentrations of the drug. On reducing the dose of MMWH to a level with $c_{\max }$ similar to that of UFH and enoxaparin, the corresponding $\mathrm{AUC}_{0-24 \mathrm{~h}}$ would still be higher than those of UFH and enoxaparin.

The comparison of further pharmacokinetic parameters confirmed that MMWH differs from UFH as well as LMWH. It can be considered as an advantage that the $\mathrm{t} 1 / 2_{\mathrm{el}}$ and the MRT of the alla activity of MMWH are significantly longer than those of its aPTT activity. Consequently, in contrast to UFH and enoxaparin, the most important pharmacological action is the longest detectable in plasma.

In the present study, we limited ourselves to reporting the data obtained with the classically used assays for the heparin determinations to facilitate comparison with publications on other heparins. According to the pharmacokinetic data, MMWH might be suitable for s.c. administration once daily. Further, the re- 
sults of this study suggest that the appropriate doses may be lower than those of LMWH and UFH; this conclusion can obviously be substantiated only by dosefinding studies.

After s.c. administration of $9000 \mathrm{aXa}-\mathrm{U}$ each, MMWH was shown to release $43 \%$ and $59 \%$ more free TFPI $\left(\mathrm{AUC}_{0-24 \mathrm{~h}}\right)$ than UFH and enoxaparin. ${ }^{24}$ This may be considered an additional asset. It is probably caused by a favorable compromise between the increase of TFPI-releasing potency with MW and the increase of bioavailability with decreasing MW.

In conclusion, MMWH is a heparin with an average MW between that of UFH and LMWH and with a particularly narrow MW distribution. In this way, it contains neither molecules with $\mathrm{MW}>15 \mathrm{kD}$, as are characteristic of UFH, nor short-chain molecules (BCLM) exhibiting aXa activity only. It thus combines the favorable bioavailability of LMWH with the high specific anticoagulant activity of UFH. There are good reasons to believe that MMWH is the "pure" specifically acting working core of any natural heparin preparation. It may therefore be more efficient and possibly also safer than other heparins, especially because substantially lower doses (on a weight and a molar basis) are sufficient to bring about effects comparable to those of UFH and LMWH.

\section{ACKNOWLEDGMENTS}

We are grateful for financial support by the NovartisStiftung für Therapeutische Forschung, Nuremberg, Germany.

\section{REFERENCES}

1. Hirsh J, Warkentin TE, Shaughnessy SG, et al. Heparin and low-molecular-weight heparin: mechanisms of action, pharmacokinetics, dosing considerations, monitoring, efficacy, and safety. Chest 2001;119(Suppl 1):64S-94S

2. Dolovich LR, Ginsberg JS, Douketis JD, Holbrook AM, Cheah G. A meta-analysis comparing low-molecular-weight heparins with unfractionated heparin in the treatment of venous thromboembolism: examining some unanswered questions regarding location of treatment, product type, and dosing frequency. Arch Intern Med 2000;160:1881-1888

3. Young E, Wells P, Holloway S, Weitz J, Hirsh J. Ex-vivo and in-vitro evidence that low molecular weight heparins exhibit less binding to plasma proteins than unfractionated heparin. Thromb Haemost 1994;71:300-304

4. Barzu T, Molho P, Tobelem G, Petitou M, Caen J. Binding and endocytosis of heparin by human endothelial cells in culture. Biochim Biophys Acta 1985;845:196-203

5. Sarret M, Kher A, Toulemonde F. Low Molecular Weight Heparin Therapy. 1st ed. New York: Marcel Dekker; 1999

6. Hirsh J, Weitz JI. New antithrombotic agents. Lancet 1999; 353:1431-1436

7. Weitz JI, Hirsh J: New anticoagulant drugs. Chest 2001; 119(Suppl 1):39S-63S
8. Walenga JM, Jeske WP, Samama MM, et al. Fondaparinux: a synthetic heparin pentasaccharide as a new antithrombotic agent. Expert Opin Investig Drugs 2002;11:397-407

9. Shen GX. Development and current applications of thrombinspecific inhibitors. Current drug targets-cardiovascular \& haematological disorders 2001;1. Available at: http://www. bentham.org/cdtchd1-1/shen/shen.htm

10. Gustafsson D, Nystrom J, Carlsson S, et al. The direct thrombin inhibitor melagatran and its oral prodrug $\mathrm{H} 376 / 95$. Intestinal absorption properties, biochemical and pharmacodynamic effects. Thromb Res 2001;101:171-181

11. Lindhout $T$, Blezer $R$, Hemker $H C$. The anticoagulant mechanism of action of recombinant hirudin (CGP 39393) in plasma. Thromb Haemost 1990;64:464-468

12. Herault JP, Bernat A, Gaich C, Herbert M. Effect of new synthetic heparin mimetics on whole blood thrombin generation in vivo and in vitro in rats. Thromb Haemost 2002;87: 238-244

13. Béguin S, Welzel D, Al Dieri A, Hemker HC. Conjectures and refutations on the mode of action of heparins. Haemostasis 1999;29:170-188

14. Béguin S, Lindhout T, Hemker HC. The mode of action of heparin in plasma. Thromb Haemost 1988;60:457-462

15. Sandset PM, Abildgaard U, Larsen ML. Heparin induces release of extrinsic coagulation pathway inhibitor (EPI). Thromb Res 1988;50:803-813

16. Abildgaard U, Lindahl AK, Sandset PM. Heparin requires both antithrombin and extrinsic pathway inhibitor for its anticoagulant effect in human blood. Haemostasis 1991;21: 254-257

17. Valentin S, Ostergaard P, Kristensen H, Nordfang O. Synergism between full length TFPI and heparin: evidence for TFPI as an important factor for the antithrombotic activity of heparin [letter]. Blood Coagul Fibrinolysis 1992;3:221-222

18. Abildgaard U. Heparin/low molecular weight heparin and tissue factor pathway inhibitor. Haemostasis 1993;23(Suppl 1):103-106

19. Linhardt RJ, Toida T. Heparin oligosaccharides: new analogues development and applications. In: Witczak ZJ, Nieforth KA, eds. Carbohydrates in Drug Design. New York: Marcel Dekker; 1997:277-341

20. Zacharski LR, Ornstein DL. Heparin and cancer. Thromb Haemost 1998;17:289-297

21. Linhardt RJ, Loganathan D, al-Hakim A, et al. Oligosaccharide mapping of low molecular weight heparins: structure and activity differences. J Med Chem 1990;33:1639-1645

22. Choay J, Petitou M, Lormeau JC, et al. Structure-activity relationship in heparin. A synthetic pentasaccharide with high affinity for antithrombin $\mathrm{III}$ and eliciting high anti-factor Xa activity. Biochem Biophys Res Commun 1985;128:134-140

23. Valentin S, Larnkjer A, Ostergaard P, Nielsen JI, Nordfang O. Characterization of the binding between tissue factor pathway inhibitor and glycosaminoglycans. Thromb Res 1994;75: 173-183

24. Alban S, Gastpar R. Plasma levels of total and free tissue factor pathway inhibitor (TFPI) as individual pharmacological parameters of various heparins. Thromb Haemost 2001;85:824-829

25. Witt I, Beeser H, Müller-Berghaus G. Minimalanforderungen zur Gewinnung von Citratplasma für hämostaseologische Analysen. Lab Med 1995;19:143-145

26. Gibaldi M, Perrier D. Pharmacokinetics. 2nd ed. New York: Marcel Dekker; 1992

27. Rowland M, Tozer TN. Clinical Pharmacokinetics. Concepts and Applications. Philadelphia: Lea \& Febiger; 1989: 459-461 
28. Yamaoka K, Nakagawa T, Uno T. Statistical moments in pharmacokinetics. J Pharmacokinet Biopharm 1978;6:547558

29. Generica, Version 2.0, Prof. Dr. R. Zincke, Coesfeld, Germany, 1989

30. Holmer E, Mattsson C, Nilsson S. Anticoagulant and antithrombotic effects of heparin and low molecular weight heparin fragments in rabbits. Thromb Res 1982;25:475485

31. Ockelford PA, Carter CJ, Mitchell L, Hirsh J. Discordance between the anti- $\mathrm{Xa}$ activity and the antithrombotic activity in an ultra-low molecular weight heparin fraction. Thromb Res 1982;28:401-409

32. Thomas DP, Merton RE, Barrowcliffe TW, Thunberg L, Lindahl U. Effects of heparin oligosaccharides with high affinity for antithrombin III in experimental venous thrombosis. Thromb Haemost 1982;47:244-248

33. Bergqvist D, Nilsson B, Hedner U, Pedersen PC, Ostergaard $\mathrm{PB}$. The effect of heparin fragments of different molecular weights on experimental thrombosis and haemostasis. Thromb Res 1985;38:589-601

34. Thomas DP, Merton RE, Gray E, Barrowcliffe TW. The relative antithrombotic effectiveness of heparin, a low molecular weight heparin, and a pentasaccharide fragment in an animal model. Thromb Haemost 1989;61:204-207
35. Hoppensteadt DA, Jeske W, Ahsan A, Walenga JM, Fareed J. Biochemical and pharmacologic profile of defined molecular weight fractions of heparin. Semin Thromb Hemost 1993; 19:12-19

36. Samama MM, Bara L, Gerotziafas GT. Mechanisms for the antithrombotic activity in man of low molecular weight heparins (LMWHs). Haemostasis 1994;24:105-117

37. Greinacher A, Alban S, Dummel V, Franz G, MuellerEckhardt C. Characterization of the structural requirements for a carbohydrate based anticoagulant with reduced risk of inducing the immunological type of heparin-associated thrombocytopenia. Thromb Haemost 1995; 74:886-892

38. Warkentin TE, Levine MN, Hirsh J, et al. Heparin-induced thrombocytopenia in patients treated with low molecular weight heparin or unfractionated heparin. N Engl J Med 1995;332:1330-1335

39. Ockelford PA, Carter CJ, Cerskus A, Smith CA, Hirsh J. Comparison of the in vivo hemorrhagic and antithrombotic effects of a low antithrombin-III affinity heparin fraction. Thromb Res 1982;27:679-690

40. Cade JF, Buchanan MR, Boneu B, et al. A comparison of the antithrombotic and haemorrhagic effects of low molecular weight heparin fractions: the influence of the method of preparation. Thromb Res 1984;35:613-625 